\title{
Rapid detection of Salmonella enterica in food samples by a novel approach with combination of sample concentration and direct PCR
}

Chidambara, Vinayaka Aaydha ; Ngo Anh, Tien ; Kant, Krishna; Engelsmann, Pia; Dave, Vivek Priy; Shahbazi, Mohammad-Ali; Wolff, Anders; Bang, Dang Duong

\section{Published in:}

Biosensors and Bioelectronics

Link to article, DOI:

10.1016/j.bios.2018.09.078

Publication date:

2019

Document Version

Peer reviewed version

Link back to DTU Orbit

Citation (APA):

Chidambara, V. A., Ngo Anh, T., Kant, K., Engelsmann, P., Dave, V. P., Shahbazi, M-A., Wolff, A., \& Bang, D. D. (2019). Rapid detection of Salmonella enterica in food samples by a novel approach with combination of sample concentration and direct PCR. Biosensors and Bioelectronics, 129, 224-230. https://doi.org/10.1016/j.bios.2018.09.078

\section{General rights}

Copyright and moral rights for the publications made accessible in the public portal are retained by the authors and/or other copyright owners and it is a condition of accessing publications that users recognise and abide by the legal requirements associated with these rights.

- Users may download and print one copy of any publication from the public portal for the purpose of private study or research.

- You may not further distribute the material or use it for any profit-making activity or commercial gain

- You may freely distribute the URL identifying the publication in the public portal 


\section{Author's Accepted Manuscript}

Rapid detection of Salmonella enterica in food samples by a novel approach with combination of sample concentration and direct PCR

Aaydha C. Vinayaka, Tien A. Ngo, Krishna Kant, Pia Engelsmann, Vivek P. Dave, Mohammad-Ali Shahbazi, Anders Wolff, Dang D. Bang

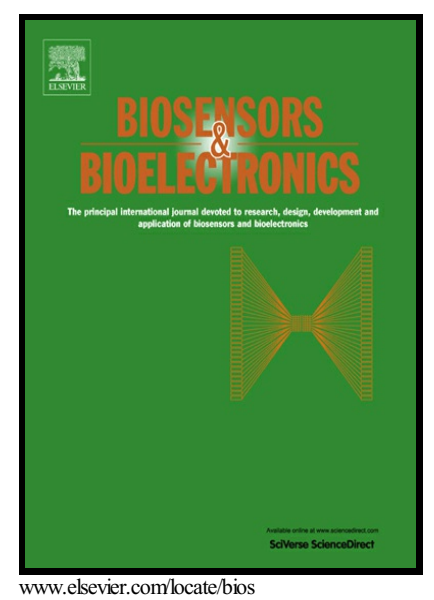

PII: $\quad$ S0956-5663(18)30775-9

DOI: $\quad$ https://doi.org/10.1016/j.bios.2018.09.078

Reference: BIOS10818

To appear in: Biosensors and Bioelectronic

Received date: 29 June 2018

Revised date: 11 September 2018

Accepted date: 21 September 2018

Cite this article as: Aaydha C. Vinayaka, Tien A. Ngo, Krishna Kant, Pia Engelsmann, Vivek P. Dave, Mohammad-Ali Shahbazi, Anders Wolff and Dang D. Bang, Rapid detection of Salmonella enterica in food samples by a novel approach with combination of sample concentration and direct PCR, Biosensors and Bioelectronic, https://doi.org/10.1016/j.bios.2018.09.078

This is a PDF file of an unedited manuscript that has been accepted for publication. As a service to our customers we are providing this early version of the manuscript. The manuscript will undergo copyediting, typesetting, and review of the resulting galley proof before it is published in its final citable form. Please note that during the production process errors may be discovered which could affect the content, and all legal disclaimers that apply to the journal pertain. 


\title{
Rapid detection of Salmonella enterica in food samples by a novel approach with combination of sample concentration and direct PCR
}

\author{
Aaydha C. Vinayaka ${ }^{1 *}$, Tien A. Ngo ${ }^{1}$, Krishna Kant ${ }^{2}$, Pia Engelsmann ${ }^{1}$, Vivek P. Dave ${ }^{1}$, \\ Mohammad-Ali Shahbazi ${ }^{2}$, Anders Wolff ${ }^{2}$ and Dang D. Bang ${ }^{1^{*}}$ \\ ${ }^{1}$ Laboratory of Applied Micro and Nanotechnology (LAMINATE), Research Group for Microbiology and \\ Hygiene, National Food Institute, Technical University of Denmark, DK-2800 Lyngby, Denmark \\ ${ }^{2}$ Department of Micro and Nanotechnology, Technical University of Denmark, DK-2800 Lyngby, Denmark \\ ddba@food.dtu.dk \\ viaa@food.dtu.dk \\ *To whom correspondence should be addressed: Tel: +45 358873 82; fax: +45 35887001
}

\section{Abstract}

Foodborne salmonellosis remains a major economic burden worldwide and particularly for food industries. The diverse and complexity of food matrices pose great challenges for rapid and ultra-sensitive detection of Salmonella in food samples. In this study, combination of pathogen pre-concentration with rapid molecular identification is presented to overcome these challenges. This combination enabled effective real-time PCR detection of low levels of Salmonella enterica serovar Typhimurium without culture enrichment. Antisalmonella antibody, immobilized on protein AG-magnetic beads, could efficiently concentrate Salmonella Typhimurium with a capturing efficiency of $95 \%$. In the direct PCR, a strong linear relationship between bacteria concentration and the number of cycles was observed with a relative PCR efficiency of $\sim 92 \%$ resulting in a limit of detection (LoD) of $\sim 2$ $\mathrm{CFU} / \mathrm{mL}$. Analysis of spiked food samples that include vegetable salad, egg yolk, egg white, whole egg and minced pork meat has validated the precision of the method. A relative accuracy of $98.3 \%$ with a sensitivity of $91.6 \%$ and specificity of $100 \%$ was achieved in the Salmonella spiked food samples. The use of a Phusion hot start DNA polymerase with a high tolerance to possible PCR inhibitors allowed the integration of direct PCR, and thereby reducing the duration of analysis to less than 3 hours. The Cohen's kappa index showed excellent agreement (0.88) signifying the capability of this method to overcome the food matrix effects in rapid and ultra-sensitive detection of Salmonella in food. This approach may lay a future platform for the integration into a Labon-a-chip system for online monitoring of foodborne pathogens. 
Keywords: Sample concentration, Salmonella detection, Direct PCR, Immuno-magnetic beads, Food safety

\section{Introduction}

Non-typhoidal Salmonella enterica is one of the leading causes of foodborne illness worldwide and represents a considerable burden in both developing and developed countries (EFSA and ECDC, 2018; WHO, 2018). Gastroenteritis and diarrheal diseases due to Salmonella species accounts for 94 million cases and 155,000 deaths globally every year (Majowicz et al., 2010). Salmonellosis is the second most commonly reported foodborne infection in the European Union (EU) and in the United States (US). European Food Safety Authority (EFSA) has estimated that over 90,000 salmonellosis cases are being reported every year in the EU, resulting in an overall economic burden as high as EUR 3 billion a year (ECDC, 2018; EFSA and ECDC, 2017). In the USA, Salmonella species accounts for approximately $34 \%$ of the outbreaks imposing an estimated economic burden of $\$ 3.7$ billion in a typical year (CDC, 2017; Hoffmann et al., 2015). More than $75 \%$ of the Salmonella outbreaks were attributed to seeded vegetables, egg, chicken, pork, beef, or vegetable row crops (IFSAC, 2017). Conventional bacterial culture methods of Salmonella detection in food samples require time-consuming enrichment step followed by selective plating, biochemical and/or serological identification. These techniques are not ideal for products with an inherently short shelf life e.g. salad, egg or ready to eat foods that are minimally processed (López-Campos et al., 2012). In recent years, several real time quantitative PCR (qPCR)-based techniques have been developed to detect salmonella in various food samples as an alternative (Almeida et al., 2013; Schuurman et al., 2007). DNA purification being the prerequisite to the qPCR is a time-consuming step and may compromise with sensitivity due to recovery loss. Inhibition of qPCR originating from the food sample presents additional concerns that can drastically reduce the sensitivity and the amplification efficiency and thereby affecting the accuracy and quantification (Rådström et al., 2008). In this direction, Phusion high-fidelity DNA polymerases $(P f u)$ has emerged as a potential alternative to overcome PCR inhibitors (Wang et al., 2004). Pfu DNA polymerase that has been fusion with a double-strand DNAbinding domain (Sso7d) show good processivity, high catalytic activity and enzyme stability. The Sso7d protein improves the performance of the Pfu DNA polymerase by 
guiding negative supercoiling (López-García et al., 1998), increasing the tolerance to high salt concentration and other PCR inhibitors. The feasibility of this reengineered DNA polymerase has recently been demonstrated for detecting pathogens in food and animal samples at slaughter (Chin et al., 2017).

The diverse and complexity of food matrices may also pose great challenges for the development of a rapid and ultra-sensitive detection methods. Sample preparation is the most challenging problem in the direct food sample analysis. This may be due to the heterogeneity of the food matrices, the non-uniform distribution of pathogens and low abundance of target pathogens in the food. In addition, the presence of indigenous microflora can often interfere with selective identification and limited measurement volumes can limit the sensitivity (Kretzer J.W., Biebl M., 2008; Mandal et al., 2011). Therefore, sample preparation and concentration process is the most critical step concerning the applicability of novel methods. In this direction, immunomagnetic separation method have been applied for selective concentration of target bacterial pathogens in order to eliminate the effects of PCR inhibitors and to reduce the heterogeneity of food samples (Fedio et al., 2011; Hyeon and Deng, 2017; Zheng et al., 2016 , 2014). However, in these studies, a minimum of 4 hrs of culture enrichment followed by DNA extraction or complex multi step approach were adopted.

In response to the demand for rapid analysis and simple strategy suitable for at-site detection of pathogens, in this study, a novel approach of combination of sample concentration and Phusion DNA polymerases-based direct PCR is described. Protein A/G was used as a bio-adapter to immobilize anti-salmonella antibodies on the magnetic beads to concentrate Salmonella directly from the food samples. The use of protein $A / G$ for controlling the orientation of antibodies in order to maximize the capacity of pathogen recognition with high sensitivity is emphasized. The performance of the direct PCR on the pathogen captured magnetic beads without DNA extraction and pre-PCR purification is evaluated.

\section{Methods}

\subsection{Optimization of immuno-magnetic bead concentration for direct PCR}


Immuno-magnetic bead conjugate was prepared by immobilizing anti-salmonella antibodies on the protein $A / G$ magnetic beads according to the manufacturer's instructions (See supplementary materials for details). The direct PCR was performed on $0.1 \mu \mathrm{g}, 1 \mu \mathrm{g}$, $10 \mu \mathrm{g}$ and $100 \mu \mathrm{g}$ of anti-salmonella antibody-bead conjugates (Ab-bead) in separate experiments using Phusion Human Specimen Direct PCR Kit in $10 \mu \mathrm{L}$ reaction volume. Initially, the Ab-bead conjugates were transferred to PCR tubes and mixed with $6 \mu \mathrm{L}$ of a direct PCR mixture containing $200 \mathrm{nM}$ of hilA primers (F: 5'GCGACGCGGAAGTTAACGAAGA-3', R: 5'-GCAGACTCTCGGATTGAACCTGATC-3') targeting the transcriptional regulator hilA gene of Salmonella Typhimurium (CCUG 31969), 1X Phusion® human specimen PCR buffer, $0.04 \mathrm{U} / \mu \mathrm{L}$ Phusion human specimen DNA polymerase and $2 X$ SYBR $^{\circledR}$ Green DNA intercalating dye (Chin et al., 2017). Prior to the PCR, an overnight culture of Salmonella Typhimurium $\left(10^{4} \mathrm{CFU}\right.$ in $\left.4 \mu \mathrm{L}\right)$ were added. The real-time PCR was conducted in Mx3005P qPCR Systems (Agilent Technologies, USA) under the PCR condition of $98^{\circ} \mathrm{C}$ for $10 \mathrm{~min}$ following by 38 cycles of $98^{\circ} \mathrm{C}$ for $10 \mathrm{~s}$, $60{ }^{\circ} \mathrm{C}$ for $15 \mathrm{~s}$ and $72^{\circ} \mathrm{C}$ for $30 \mathrm{~s}$. Further, the PCR amplified products were confirmed by $2 \%$ agarose gels electrophoresis containing 1 X SYBR ${ }^{\circledR}$ Safe DNA gel stain (Invitrogen, Life Technologies, USA) and the gel image captured (Gel Doc 2000, Bio-Rad) was assessed by ImageJ software (https://imagej.nih.gov/ij/).

\subsection{Studies on the direct PCR assay efficiency and sensitivity}

\subsubsection{Salmonella concentration and the estimation of capturing efficiency}

An immuno-magnetic bead-based Salmonella concentration method was developed in the present study (Scheme 1) and the capturing efficiency was estimated. $10 \mu \mathrm{g}$ of the Abbead conjugate that corresponds to $\sim 5^{\star} 10^{6}$ beads (See supplementary materials for details) were mixed with $2.4 * 10^{4} \mathrm{CFU}$ of Salmonella Typhimurium spiked in $1 \mathrm{~mL}$ of $10 \mathrm{mM}$ PBST. The mixture was incubated at $37^{\circ} \mathrm{C}$ for 30 minutes and concentrated using the magnetic stand. The supernatant was preserved and $100 \mu \mathrm{L}$ of $1: 10$ dilution was plated on a BA plates in duplicates and incubated overnight at $37^{\circ} \mathrm{C}$. The concentrated beadSalmonella Typhimurium complex was washed 4 times with $1 \mathrm{~mL}$ of PBST. $100 \mu \mathrm{L}$ of each 
washing solution were plated directly on BA plates. The efficiency of Ab-bead to capture Salmonella was estimated by bacterial culture colony count (CFU) method.

\subsubsection{Evaluation of assay sensitivity and PCR efficiency}

In order to evaluate the direct PCR efficiency, initially, a standard graph of Salmonella Typhimurium was generated by qPCR method. A serial 10-fold dilution of Salmonella Typhimurium in $1 \mathrm{~mL}$ of PBS was prepared from a stock culture $\left(O . D_{600}=0.8\right.$, corresponding to $5.64^{*} 10^{8} \mathrm{CFU} / \mathrm{mL}$ as calculated by colony counting method). One $\mu \mathrm{L}$ of each dilution of Salmonella Typhimurium was added to a PCR solution containing $10 \mu \mathrm{g}$ of ab-bead conjugate ( $10 \mu \mathrm{L}$ final volume) to give a final concentration ranging from 6 to $5.64^{*} 10^{5} \mathrm{CFU} / 10 \mu \mathrm{L}$ PCR reaction in triplicates. The Direct PCR was conducted as mentioned earlier. Ct values (cycle threshold) obtained for each concentration was plotted against the $\log _{10}$ concentration (CFU) of Salmonella Typhimurium.

To test the sensitivity of the developed integrated immuno-magnetic direct PCR method, serial dilution of Salmonella Typhimurium cells were spiked in $1 \mathrm{~mL}$ of $10 \mathrm{mM}$ PBST to give a final concentrations ranging from 6 to $6.6^{*} 10^{4} \mathrm{CFU} / \mathrm{mL}$ in triplicates. A nonspiked sample was included as a negative control. The spiked pathogen samples were concentrated using $10 \mu \mathrm{g}$ of Ab-bead conjugate and the direct PCR was conducted on these beads as mentioned in previous section (Scheme 1). The Ct values were plotted against the $\log _{10}$ of concentration of Salmonella Typhimurium spiked in the PBS. Further, the amplified PCR products were confirmed by $2 \%$ agarose gels electrophoresis. The Direct PCR amplification efficiencies $(E \%)$ for both the controls and the magnetically concentrated samples were determined based on the slope of the standard graph according to the following standard equation (Fraga et al., 2012);

$$
E(\%)=\left[10^{\left(\frac{-1}{\text { slope }}\right)}-1\right] * 100
$$

The average recovery (\%) of Salmonella Typhimurium from the spiked PBS samples was determined by interpolating the Ct values on the Salmonella Typhimurium standard 
graph. The capturing efficiency of ab-bead conjugate was estimated according to the equation S1 (supplementary material).

\subsection{Analysis of Salmonella spiked food samples}

\subsubsection{Food sample preparation and optimization of sample dilution conditions}

Fresh food samples that include mixed vegetable salad, chicken egg and minced pork meat were purchased from the local supermarket in Denmark. The samples were processed according to Nordic Committee on Food Analysis reference method (NMKL-71, http://www.nmkl.org/index.php/en/webshop/item/salmonella-pavisning-i-livsmedel-nmkl-715-utg-1999) with slight modification. Initially, $25 \mathrm{~g}$ of mixed vegetable salad, egg yolk and whole egg samples were homogenized in $25 \mathrm{~mL}$ of Buffered Peptone Water (BPW, 1:1 dilution) for 10 minutes. A minced pork meat sample was homogenized in $125 \mathrm{~mL}$ of BPW (1:5 dilutions). After thorough mixing, the mixed vegetable salad and the minced pork meat samples were filtered separately using filter stomacher bags (BagPage ${ }^{\circledR} \mathrm{R}$, Interscience, France). The respective debris free food matrix solutions was carefully collected. The mixed vegetable salad matrix was preserved till further use at $4{ }^{\circ} \mathrm{C}$.

In order to observe the effect of sample dilution on the efficiency of Salmonella concentration and direct PCR, a Salmonella Typhimurium culture of $770 \mathrm{CFU}$ in $100 \mu \mathrm{L}$ (as calculated by colony counting) was spiked into $250 \mu \mathrm{L}, 500 \mu \mathrm{L}$ and $750 \mu \mathrm{L}$ of the minced pork meat, the egg yolk, the whole egg and an undiluted egg white samples separately. The volume of the spiked samples was adjusted to $1 \mathrm{~mL}$ with $10 \mathrm{mM}$ PBST. The spiked Salmonella Typhimurium cells were concentrated from each samples separately using $10 \mu \mathrm{g}$ of Ab-bead conjugate and the direct PCR was conducted on these beads as mentioned above. Amplified PCR products were confirmed by electrophoresis using $2 \%$ agarose gel.

2.3.2. Studies on the limit of detection of immuno-magnetic bead combined direct PCR method in the Salmonella spiked food samples 
To determine the limit of detection in the spiked food samples, a 10-fold serial dilution of Salmonella Typhimurium was prepared from a stock culture $\left(O . D_{600}=\sim 0.8\right) .100 \mu \mathrm{L}$ of each dilution was spiked into $200 \mu \mathrm{L}$ of the mixed vegetable salad (1:5 dilution) and 100 $\mu \mathrm{L}$ of the minced pork meat, the egg yolk, the whole egg and the undiluted egg white samples (1:10 dilution) separately in triplicates. The volume of the spiked samples was adjusted to $1 \mathrm{~mL}$ with $10 \mathrm{mM}$ PBST to attain a final concentration gradient of Salmonella cells ranging from $10^{0}$ to $10^{4} \mathrm{CFU} / \mathrm{mL}$. A non-spiked sample was included as a negative control for each sample. The spiked pathogens were concentrated and the direct PCR was conducted as mentioned in previous section. PCR amplified products were confirmed by $2 \%$ agarose gels electrophoresis and the efficiencies $(E \%)$ of the Direct PCR amplification were determined according to the Eq. 1 for each samples.

\subsection{Evaluation of assay precision and statistical analysis}

Concentrations of Salmonella Typhimurium recovered from the spiked food samples were calculated by interpolating the mean $\mathrm{Ct}$ values of each trial on the standard curve. The efficiency of recovery (\%) was estimated by comparing the calculated concentration with the spiked concentration over the concentration gradient for each sample. Inter assay precision and repeatability of the developed technique was determined by calculating coefficient of variance (CV\%). Relative sensitivity, relative specificity and relative accuracy of the integrated immuno-magnetic direct PCR assay in the food samples were statistically evaluated based on the following relations (Chin et al., 2017)

$$
\begin{aligned}
& \text { Relative accuracy }(A C \%)=\left[\frac{(\mathrm{PA}+\mathrm{NA})}{\mathrm{N}}\right] * 100 \\
& \text { Relative specificity }(S P \%)=\left[\frac{\mathrm{NA}}{\mathrm{N}-}\right] * 100 \\
& \text { Relative sensitivity }(S E \%)=\left[\frac{\mathrm{PA}}{\mathrm{N}+}\right] * 100
\end{aligned}
$$

PA: Positive agreement (recovery) between the PBS and food samples

NA: Negative agreement (recovery) between the PBS and food samples

$\mathrm{N}$ : Total number of samples (NA+PA+PD+ND) 
PD: False positives recovery from food samples

ND: False negatives recovery from food samples

$\mathrm{N}-$ : Total number of negative results (NA+PD)

$\mathrm{N}+$ : Total number of positive results (PA+ND).

Cohen's kappa inter assay agreement was assessed between the presence and absence of different food matrix as given below (Carpentier et al., 2017; Hyeon and Deng, 2017);

Cohen's Kappa index $=\left[\frac{\mathrm{P}(o)-\mathrm{P}(e)}{1-\mathrm{P}(\mathrm{e})}\right]$

$P(0):(P A+N A) / t o t a l$ number of tested concentrations

$P(e)$ : \{ (positive recovery in the absence of food matrix / total number of tested concentrations) $\mathrm{x}$ (negative recovery in the absence of food matrix / total number of tested concentrations $)\}+\{$ (negative recovery in the presence of food matrix / total number of tested concentrations) $x$ (negative recovery in the absence of food matrix / total number of tested concentrations)\}.

\section{Results and Discussion}

\subsection{Immuno-magnetic bead combined direct PCR}

Several molecular techniques have been developed for the pathogen detection in food samples. However, these techniques involved complex multiple steps that include food matrix separation, pathogen enrichment and sample preparation followed by DNA extraction to avoid possible inhibitions of the downstream amplification (Chapela et al., 2015; Wang and Salazar, 2016). As a consequence, the detection techniques became complex with considerably long duration of analysis (Table S1, supplementary material) and limit their practical field applicability. Combination of pathogen concentration with direct PCR is the best efficient approach to avoid these limitations, since the direct PCR bypass the pre-PCR DNA extraction/purification steps (Chin et al., 2017). In this study, a combined approach was adopted to concentrate Salmonella Typhimurium cells from food 
samples using antibody immobilized magnetic beads and direct PCR was performed without DNA extraction/purification steps (Scheme 1).

\subsubsection{Antibody immobilization and inhibitory effect of magnetic beads on the direct PCR method}

Strategy to control the immobilization of antibodies on a surface has been the critical parameter in any affinity reactions to retain orientation of antibodies. Immobilization with an appropriate orientation places antibodies in an ideal position to maximize the capacity of antigen recognition (Hermanson, 2013). Protein $A / G$ is known for recognizing the Fc (Fragment crystallizable) domain of an antibody that results in unidirectional orientation of immobilized antibodies. Therefore in this study, protein $A / G$ was used as a bio-adapter to immobilize specifically anti-salmonella antibodies on the magnetic beads. Using this strategy a significant reduction in the absorbance of the antibody-bead conjugate supernatant at $280 \mathrm{~nm}$ after overnight incubation was observed and an immobilization efficiency of more than $98 \%$ was achieved. The result is in accordance with the manufacturer's claims.

The use of magnetic beads have been proven to be effective in obtaining high sensitivity and selectivity in the pathogen detection (Sun et al., 2015). In an initial experiment it appeared that the uninhibited direct PCR on the magnetic beads needs optimal concentration of Ab-bead conjugate. In order to investigate the possible inhibitory effect of the magnetic bead on the direct PCR, the direct PCR was performed with $0.1 \mu \mathrm{g}$, $1 \mu \mathrm{g}, 10 \mu \mathrm{g}$ and $100 \mu \mathrm{g}$ of Ab-bead conjugates. This corresponds to $4.8^{\star}\left(10^{4}, 10^{5}, 10^{6}\right.$, and $10^{7}$ ) magnetic bead particles respectively used for the inhibitory tests. The numbers of beads were calculated based on the diameter $(1.254 \mu \mathrm{M})$ and the density $\left(2 \mathrm{~g} / \mathrm{cm}^{3}\right)$ of the beads (See supplementary material for details). The use of magnetic beads showed no inhibitory effect at all on direct PCR even at concentration of $4.8^{*} 10^{7}$ beads per $10 \mu \mathrm{L}$ of PCR reaction (Fig. S2A). In these experiments $\mathrm{Ct}$ values from the real-time PCR amplification curves were used as indicators of the inhibitory effects, since significant decreases in PCR efficiency would result in delayed response. A specific amplification of 
225 bp of the hilA gene (Chin et al., 2017) was obtained that was confirmed in the electrophoresis gel image (Fig. S2B). Analysis of gel image with ImageJ software revealed insignificant differences in the amplified copy numbers (Fig. S2C). This has unlocked the prospect of integrating pathogen concentration and direct amplification of captured Salmonella Typhimurium with reduced assay complexity and analysis time.

\subsubsection{Pathogen concentration using magnetic beads}

Anti-salmonella antibody immobilized magnetic beads tested for direct PCR compatibility was used to capture Salmonella Typhimurium cells. $10 \mu \mathrm{g}$ of Ab-bead conjugate having 598 ng of immobilized antibody in total was used in the capturing experiments. The protein AG capped magnetic bead used in this study had a binding capacity of $61 \mu \mathrm{g}$ of antibody per $1 \mathrm{mg}$ of bead, according to the manufacturer. SEM images confirm the capturing of Salmonella Typhimurium on the beads (Fig.1). An intact rod shaped Salmonella can be seen at higher magnification that was attached to the beads even after multiple washings (Fig. 1C).

\subsection{Efficiency and sensitivity of integrated immuno-magnetic direct PCR method}

The feasibility of pathogen concentration in combination with direct PCR approach was initially optimized using Salmonella Typhimurium spiked PBS. The magnetic bead-based approach had a capturing efficiency of $>95 \%$. This was calculated by counting colonies left out in the reaction supernatant after magnetic concentration (Table 1). The capturing efficiencies were also determined based on the ratio of inverse of the slopes obtained in the real-time direct PCR for Salmonella Typhimurium before spiking and after recovering Salmonella Typhimurium from PBS (Fig. 2A, 2B). According to the slopes the estimated capturing efficiency was around $94 \%$ within concentration ranging from 6 to $6.4^{*} 10^{4}$ $\mathrm{CFU} / \mathrm{mL}$. This was in agreement with the capturing efficiency calculated by bacterial culture and colony counting method (CFU).

The Direct PCR standard curve generated in the presence of Ab-bead was used to relatively quantify Salmonella Typhimurium concentrated from the PBS. For the precise quantification, it is necessary to have similar reaction kinetics and PCR efficiency for samples and the standards (Hedman et al., 2013). In this study, the performance of the 
direct PCR was not affected by the presence of magnetic beads. However, it is worth mentioning that there was a delay of approximately 1.5 cycles to reach the threshold fluorescence in the presence of magnetic beads (Fig. S2 A and S2 B). The direct PCR had an efficiency of $87.17 \%$ in the presence of magnetic beads and $100.85 \%$ in the absence of magnetic beads (Fig. 2A, Eq. 1). The difference in the Ct value due to delayed response is an indication of possible inhibitory effects that may results in decreased PCR efficiency (Kralik and Ricchi, 2017). In general, PCR inhibitors are commonly classified as polymerase inhibitors, nucleotide inhibitors and fluorescence inhibitors in particular that interfere with the detection of amplicon during qPCR (Hedman et al., 2013; Schrader et al., 2012). The Pierce protein $A / G$ magnetic beads used in this study had a proprietary doubleshell design. The central polymeric core was double-coated with magnetite and sealed with an outer hydrophilic polymer encapsulation surface. This was further covalently coupled with protein $\mathrm{A} / \mathrm{G}$ monolayer (Protein Biology Application Notes, https://www.thermofisher.com). This may, probably, limit the chances of inhibitions of polymerase and nucleotides. However, this possibility may not be completely ruled out simply because mechanism of PCR inhibition of most of the compounds is not completely known. It was reported that materials with strong background color may interfere with fluorescence detection by simply masking or obstructing the fluorescence (Hedman et al., 2013; Opel et al., 2010). The protein AG magnetic bead had an inherent brownish color. Thus, the difference in the slope of the standard curves may be attributed to the small interference of magnetic beads on the SYBR green fluorescence during the direct PCR (Fig. 2A). In order to confirm this possible effect, total fluorescence of qPCR product (10 $\mu \mathrm{L}$ reaction solution after 35 cycles) with SYBR green was recorded both in the presence and absence of $10 \mu \mathrm{g}$ of Ab-bead by simply mixing the bead with $\mathrm{qPCR}$ product. A reduction $(\sim 8-9 \%)$ in the SYBR green fluorescence intensity was observed in the presence of $10 \mu \mathrm{g}$ of Ab-bead conjugate that has confirmed this possibility (Fig. S2 A, Fig. S3 A, B, C). Similarly, a difference observed between the slopes of two standard curves was $\sim 10 \%$ (Fig. 2A) that has further supported the possibility. Therefore, the direct PCR standard curve that was generated in the presence of magnetic beads was used to relatively quantify Salmonella Typhimurium concentrated from spiked samples (Fig. 2A). Accordingly, pathogen concentration combined direct PCR approach showed convincing detection sensitivity. It was possible to concentrate Salmonella Typhimurium at a 
concentration as low as $6 \mathrm{CFU} / \mathrm{mL}$ from PBS and performing direct PCR on those beads (Fig. S4 and S5). A strong linear relationship $\left(R^{2}=0.9931\right)$ was observed between $\mathrm{Ct}$ values and the tested concentrations (Fig. 2B). The relative PCR efficiency was $\sim 92 \%$ in comparison with standard graph generated in the presence of magnetic bead (Table 1).

\subsection{Evaluation of the integrated immuno-magnetic direct PCR method with Salmonella spiked food samples}

\subsubsection{Effect of food matrix on the direct PCR efficiency and assay sensitivity}

The developed integrated immuno-magnetic direct PCR method was used to test different food samples that include vegetable salad, egg white, egg yolk, whole egg and minced pork meat samples. It was possible to detect Salmonella Typhimurium within concentration ranging from $\sim 6$ to $6.4^{*} 10^{4} \mathrm{CFU} / \mathrm{mL}$ in all the tested food samples except for the egg white (Fig. 3). The relative PCR efficiency was between $\sim 81 \%$ and $\sim 94 \%$ (Table 1 ). In the egg white sample, the detection range was between $\sim 65$ to $6.4^{*} 10^{4} \mathrm{CFU} / \mathrm{mL}$ with a relative PCR efficiency of $67.3 \%$ (Fig. 3D, Table 1). This reduction in the relative PCR efficiency was attributed to the combined effect of capturing efficiency and possible PCR inhibition. The glycoproteins and fats that predominate the composition in the egg white and yolk respectively (Parkinson, 1966) may interfere with sample concentration and PCR. Besides, the food matrix may also affect the pathogen capturing efficiency (Wang et al., 2016). The minced pork meat and the vegetable salad samples are complex matrix and often contains high background of different types of PCR inhibitors, normal microbiota and microflora (Schrader et al., 2012). Monteiro et al. reported that sample dilution can be a simple strategy to reduce the effects of PCR inhibitors (Monteiro et al., 1997). The effect of dilution ratio on the efficiency of direct PCR was also studied in our group previously and a dilution ratio of 1:10 was recommended (Chin et al., 2017). Hence, a dilution ratio of 1:10 was implemented in this study for concentrating Salmonella Typhimurium from the food samples. It is worth to mention that lower dilutions were also studied initially; however, the PCR results were inconsistent and were not reproducible (Fig. S6). At a dilution ratio of $1: 10$ the capturing efficiency was between $85 \%$ and $95 \%$ (Table 1). This was consistent at lower concentrations of spiked Salmonella Typhimurium also as evident from the gel 
images (Fig. 3C and insets). Thus, the successful detection of Salmonella Typhimurium directly from spiked food samples was attributed to a number of factors. First, the magnetic beads were biocompatible with the Phusion polymerase and did not pose substantial inhibition (Fig. S2). Second, concentrating the spiked pathogen using magnetic beads was efficient in all the tested samples (Table 1). Third, the Phusion polymerase has overcome potential PCR inhibitors of the food samples because of its inherent properties such as enhanced robustness, high accuracy and higher tolerance to inhibitors. The expected positive and negative signals were observed for all assays implying that the sample concentration combined direct PCR approach was suitable for analysis of several food samples without significant interference.

\subsubsection{Statistical analysis of the integrated immuno-magnetic direct $P C R$ method}

The integrated immuno-magnetic direct PCR assay was statistically evaluated to determine the accuracy, precision and reproducibility of the method. Interpolation of the $\mathrm{Ct}$ values of magnetically concentrated sample on the standard graph estimated the recovery from the PBS. Accordingly, an average recovery of $86 \%$ was achieved with an average standard deviation (SD) of 0.66 and a median coefficient of variance (CV) of $2.3 \%$. The limit of detection (LoD) and limit of quantification (LoQ) were determined to be $\sim 2$ and 2-3 $\mathrm{CFU} / \mathrm{mL}$, respectively (supplementary material, Table S2).

Further, precision of the integrated immuno-magnetic direct PCR method was determined in the spiked food samples. In comparison with PBS, this integrated method failed to detect Salmonella Typhimurium at concentration of $6 \mathrm{CFU} / \mathrm{mL}$ in the minced pork meat and in the egg white samples (Fig. 3C). A total number of 60 spiked food samples were tested of which 55 samples were detected positive. This results into a relative accuracy, specificity and sensitivity of $98.3 \%, 100 \%$ and $91.6 \%$, respectively (Table 2). Achieving a relative specificity of $100 \%$ was obvious in this assay because of two reasons. First, the antibody used in this study for concentrating Salmonella Typhimurium was highly specific to "O" (somatic lipopolysaccharide antigen) and " $H$ " (flagellar protein) antigens of Salmonella spp. Second, the hilA gene of Salmonella is known to be highly specific for Salmonella enterica subspecies Enterica (Cardona-Castro et al., 2002). Chin et al., (2017) has demonstrated the specificity of the hilA gene primers to differentiate 15 different 
Salmonella serotypes from 16 non-Salmonella bacteria strains. This two stage specificity has overcome the possibility of false positive results. The Cohen's kappa index showed excellent agreement (Cohen's kappa $=0.88$ ). In addition, the assay can be completed within 3 hrs with a LoD of $\sim 2 \mathrm{CFU} / \mathrm{mL}$ that include sample concentration and specific detection in food samples, which is much better than previously reported studies (Table S1 and S3). This signifies the capability of integrated immuno-magnetic direct PCR method to overcome matrix effects in rapid and ultra-sensitive detection of food borne pathogens.

\section{Conclusions}

The combination of pathogen concentration and direct PCR strategy was presented in this study as a novel approach for the detection of Salmonella Typhimurium directly from food samples without bacterial culturing, DNA isolation and purification steps. The use of magnetic beads in combination with the direct PCR had highly acceptable and reproducible capturing efficiency and PCR amplification efficiency respectively. In contrast to the conventional PCR, the method enabled rapid and ultra-sensitive detection of Salmonella Typhimurium at concentrations as low as 2-3 CFU/mL within $3 \mathrm{hrs}$. The high precision achieved in this integrated immuno-magnetic direct PCR approach with a relative accuracy of $98.3 \%$, a sensitivity of $91.6 \%$ and specificity of $100 \%$ signifies the potential to overcome the interference from food matrix in the foodborne Salmonella enterica detection. This integrated method also possesses potential to be used by the food industries and regulatory agencies for the detection of other pathogens to monitor food quality. The combined approach is also ideally suitable for the integration into a Lab-on-achip based biosensor system in future for online monitoring of foodborne pathogens.

\section{Acknowledgements}

This work was financially supported by the European Union's Horizon 2020 research and innovation program under the project SMARTDIAGNOS, grant agreement No. 687697. Dr. Vinayaka A.C is greatly thankful to the European Union and the Technical University of Denmark for the H.C. Ørsted fellowship co-funded under Marie Skłodowska-Curie Actions. 


\section{ACCEPTED MANUSCRIPT}

\section{Competing interests}

The authors declare no competing financial interest.

\section{Supplementary material}

Details of the reagents and the bacterial strain used in this study were provided in the supplementary material. Method followed for the preparation of immuno-magnetic bead conjugate and sample preparation for SEM studies were also provided in the supplementary material.

\section{References}

Almeida, C., Cerqueira, L., Azevedo, N.F., Vieira, M.J., 2013. Int. J. Food Microbiol. 161, 16-22. doi:10.1016/j.ijfoodmicro.2012.11.014

Cardona-Castro, N., Restrepo-Pineda, E., Correa-Ochoa, M., 2002. Mem. Inst. Oswaldo Cruz 97, 1153-1156. doi:10.1590/S0074-02762002000800016

Carpentier, M., Combescure, C., Merlini, L., Perneger, T. V., 2017. BMC Med. Res. Methodol. 17, 1-8. doi:10.1186/s12874-017-0340-6

CDC, 2017. Centers for Disease Control and Prevention (CDC). Surveillance for Foodborne Disease Outbreaks, United States, 2015, Annual Report. Atlanta, Georgia: US Department of Health and Human Services, CDC, 2017.

Chapela, M.-J., Garrido-Maestu, A., Cabado, A.G., 2015. Cogent Food Agric. 1, 1-19. doi:10.1080/23311932.2015.1013771

Chin, W.H., Sun, Y., Høgberg, J., Quyen, T.L., Engelsmann, P., Wolff, A., Bang, D.D., 2017. Mol. Cell. Probes 32, 24-32. doi:10.1016/j.mcp.2016.11.004

ECDC, 2018. Salmonellosis, in: ECDC (European Centre for Disease Prevention and Control) Annual Epidemiological Report for 2015. European Centre for Disease Prevention and Control, Stockholm, pp. 1-6. 
EFSA and ECDC, 2018. Multi-country outbreak of Salmonella Agona infections linked to infant formula. EFSA Support. Publ. 15, 1-9. doi:10.2903/sp.efsa.2018.EN-1365

EFSA and ECDC, 2017. The European Union summary report on trends and sources of zoonoses, zoonotic agents and food-borne outbreaks in 2016. EFSA J. 15, 1-228. doi:10.2903/j.efsa.2017.5077

Fedio, W.M., Jinneman, K.C., Yoshitomi, K.J., Zapata, R., Wendakoon, C.N., Browning, P., Weagant, S.D., 2011. Int. J. Food Microbiol. 148, 87-92. doi:10.1016/j.jjfoodmicro.2011.05.005

Fraga, D., Meulia, T., Fenster, S., 2012. Real-Time PCR, in: Sean R. Gallagher, Emily A. Wiley (Eds.), Current Protocols, Essential Laboratory Techniques. Wiley, pp. 1-33. doi:10.1002/9780470089941.et1003s08

Hedman, J., Knutsson, R., Ansell, R., Rådström, P., Rasmusson, B., 2013. Pract. Sci. 11, S87-S101. doi:10.1089/bsp.2012.0090

Hermanson, G.T., 2013. Immobilization of Ligands on Chromatography Supports, in: Bioconjugate Techniques. Academic Press publications, pp. 589-740. doi:10.1016/B978-0-12-382239-0.00015-7

Hoffmann, S., Maculloch, B., Batz, M., 2015. EIB-140, U.S. Dep. Agric. Econ. Res. Serv. 1-59. doi:10.1001/jamadermatol.2014.3593

Hyeon, J.Y., Deng, X., 2017. Food Microbiol. 63, 111-116. doi:10.1016/j.fm.2016.11.007

IFSAC, 2017. Interagency Food Safety Analytics Collaboration. Foodborne illness source attribution estimates for 2013 for Salmonella, Escherichia coli O157, Listeria monocytogenes, and Campylobacter using multi-year outbreak surveillance data, United States. GA and D., IFSAC project.

Kralik, P., Ricchi, M., 2017. Front. Microbiol. 8, 1-9. doi:10.3389/fmicb.2017.00108 Kretzer J.W., Biebl M., M.S., 2008. Sample Preparation - An Essential Prerequisite for 
High-Quality Bacteria Detection, in: Zourob M., Elwary S., T.A. (Ed.), Principles of Bacterial Detection: Biosensors, Recognition Receptors and Microsystems. Springer New York, New York, NY, pp. 15-30. doi:10.1007/978-0-387-75113-9_2

López-Campos, G., Martínez-Suárez, J. V., Aguado-Urda, M., López-Alonso, V., 2012. Microarray Detection and Characterization of Bacterial Foodborne Pathogens, in: SpringerBriefs in Food, Health, and Nutrition. Springer, Boston, MA, pp. 13-33. doi:10.1007/978-1-4614-3250-0

López-García, P., Knapp, S., Ladenstein, R., Forterre, P., 1998. Nucleic Acids Res. 26, 2322-2328. doi:10.1093/nar/26.10.2322

Majowicz, S.E., Musto, J., Scallan, E., Angulo, F.J., Kirk, M., O’Brien, S.J., Jones, T.F., Fazil, A., Hoekstra, R.M., 2010. Clin. Infect. Dis. 50, 882-889. doi:10.1086/650733

Mandal, P.K., Biswas, A.K., Choi, K., Pal, U.K., 2011. Am. J. Food Technol. doi:10.3923/ajt.2011.87.102

Monteiro, L., Bonnemaison, D., Vekris, A., Petry, K.G., Bonnet, J., Vidal, R., Cabrita, J., Mégraud, F., 1997. J. Clin. Microbiol. 35, 995-998.

Opel, K.L., Chung, D., McCord, B.R., 2010. J. Forensic Sci. 55, 25-33. doi:10.1111/j.15564029.2009.01245.x

Parkinson, T.L., 1966. J. Sci. Food Agric. 17, 101-111. doi:10.1002/jsfa.2740170301

Rådström, P., Löfström, C., Lövenklev, M., Knutsson, R., Wolffs, P., 2008. Strategies for overcoming PCR inhibition. Cold Spring Harb. Protoc. 3. doi:10.1101/pdb.top20

Schrader, C., Schielke, A., Ellerbroek, L., Johne, R., 2012. J. Appl. Microbiol. 113, 10141026. doi:10.1111/j.1365-2672.2012.05384.x

Schuurman, T., De Boer, R.F., Van Zanten, E., Van Slochteren, K.R., Scheper, H.R., DijkAlberts, B.G., Möller, A.V.M., Kooistra-Smid, A.M.D., 2007. J. Clin. Microbiol. 45, 3692-3700. doi:10.1128/JCM.00896-07 
Sun, Y., Quyen, T.L., Hung, T.Q., Chin, W.H., Wolff, A., Bang, D.D., 2015. Lab Chip 15, 1898-1904. doi:10.1039/C4LC01459F

Wang, X., Lin, H., Cao, L., Zhang, X., Sui, J., 2016. Food Agric. Immunol. 27, 230-241. doi:10.1080/09540105.2015.1086317

Wang, Y., Prosen, D.E., Mei, L., Sullivan, J.C., Finney, M., Vander Horn, P.B., 2004. Nucleic Acids Res. 32, 1197-1207. doi:10.1093/nar/gkh271

Wang, Y., Salazar, J.K., 2016. Compr. Rev. Food Sci. Food Saf. 15, 183-205. doi:10.1111/1541-4337.12175

WHO, 2018. Salmonella (non-typhoidal) [WWW Document]. URL http://www.who.int/en/news-room/fact-sheets/detail/salmonella-(non-typhoidal)

Zheng, Q., Mikš-Krajnik, M., Yang, Y., Lee, S.-M., Lee, S.-C., Yuk, H.-G., 2016. Int. J. Food Microbiol. 222, 48-55. doi:10.1016/j.ijfoodmicro.2016.01.013

Zheng, Q., Mikš-Krajnik, M., Yang, Y., Xu, W., Yuk, H.-G., 2014. Int. J. Food Microbiol. 186, 6-13. doi:10.1016/j.jijoodmicro.2014.06.005 


\section{ACCEPTED MANUSCRIPT}

Scheme 1. Schematic representation of the developed integrated immuno-magnetic direct PCR method

Fig. 1. SEM studies on the (A) protein AG capped magnetic beads and (B and C) Salmonella Typhimuriumbead complex after capturing.

Fig. 2. Direct $P C R$ standard curves of Salmonella Typhimurium (A) before spiking wherein direct $P C R$ was conducted in the absence of magnetic beads (-) and in the presence of magnetic beads (---). (B) Direct PCR linear curve after concentrating Salmonella Typhimurium from PBS with magnetic beads. The gel electrophoresis image (both inset A and B) confirmed specific amplification of 225 bp of hilA gene respectively. On the gel, Lane 1: negative PCR control without template, lane 2: 5-7 CFU, lane 3: $10^{1} \mathrm{CFU}$, lane 4: $10^{2} \mathrm{CFU}$, lane 5: $10^{3} \mathrm{CFU}$, lane $6: 10^{4} \mathrm{CFU}$, lane $7: 10^{5} \mathrm{CFU}$ (for both $\mathrm{A}$ and $\mathrm{B}$ ).

Fig. 3. Direct PCR linear fit curves of Salmonella Typhimurium after concentrating with magnetic beads from (A) salad sample, (B) minced pork meat, (D) egg white, (E) egg yolk and (F) whole egg. Dashed line (for all) represent standard curve of Salmonella Typhimurium generated in the presence of magnetic beads before spiking. The gel electrophoresis images (all the insets) confirmed specific amplification of $225 \mathrm{bp}$ hilA gene in all the tested concentrations. On the gel, lane 1: negative PCR control without template, lane 2: 4-7 CFU, lane 3: $10^{1} \mathrm{CFU}$, lane 4: $10^{2} \mathrm{CFU}$, lane 5: $10^{3} \mathrm{CFU}$, lane 6: $10^{4} \mathrm{CFU}$ (for all the insets). (C) Comparison of the capturing efficiency variations between different food samples as revealed by the ImageJ analysis of gel images. 


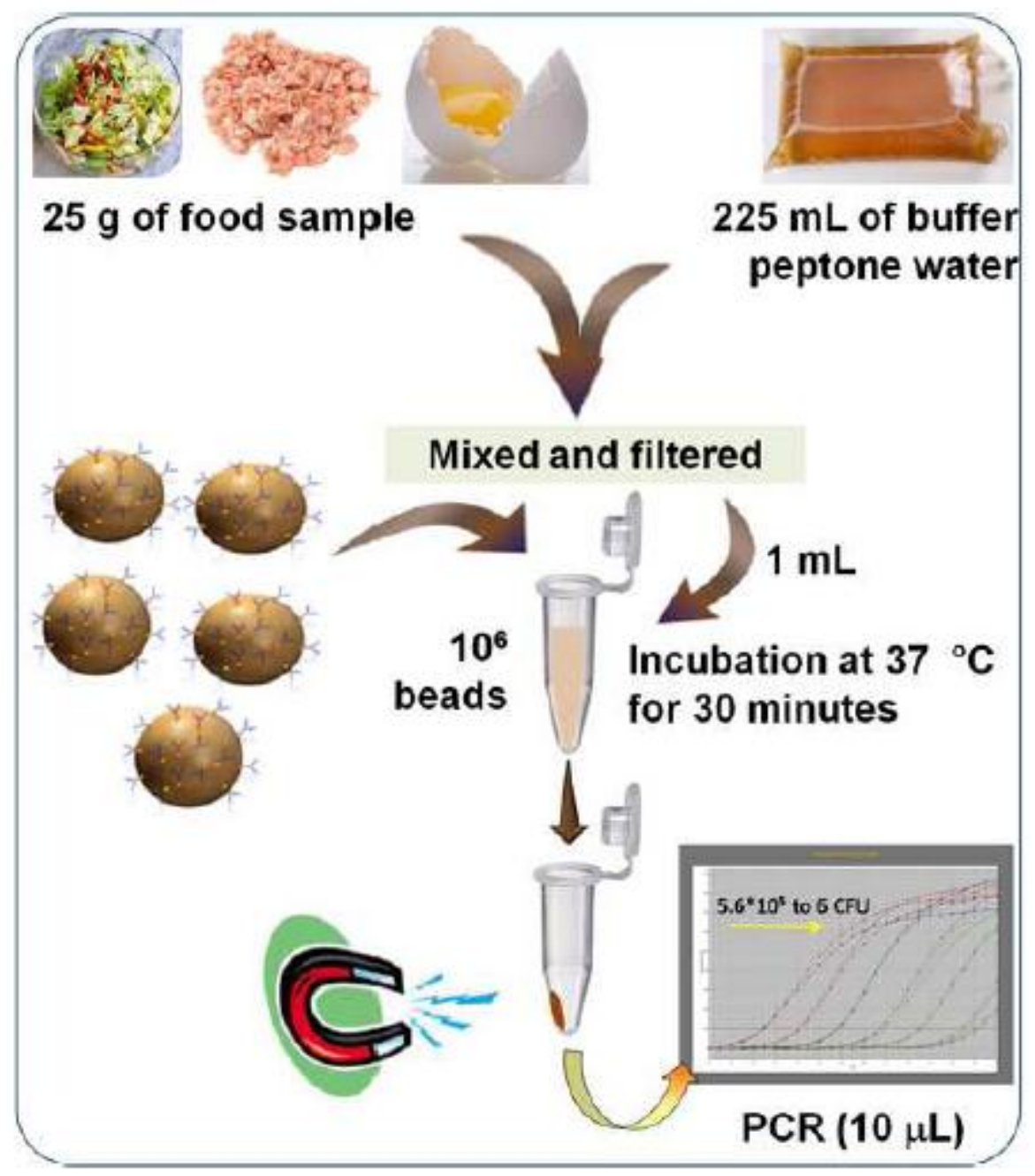

Scheme 1. 

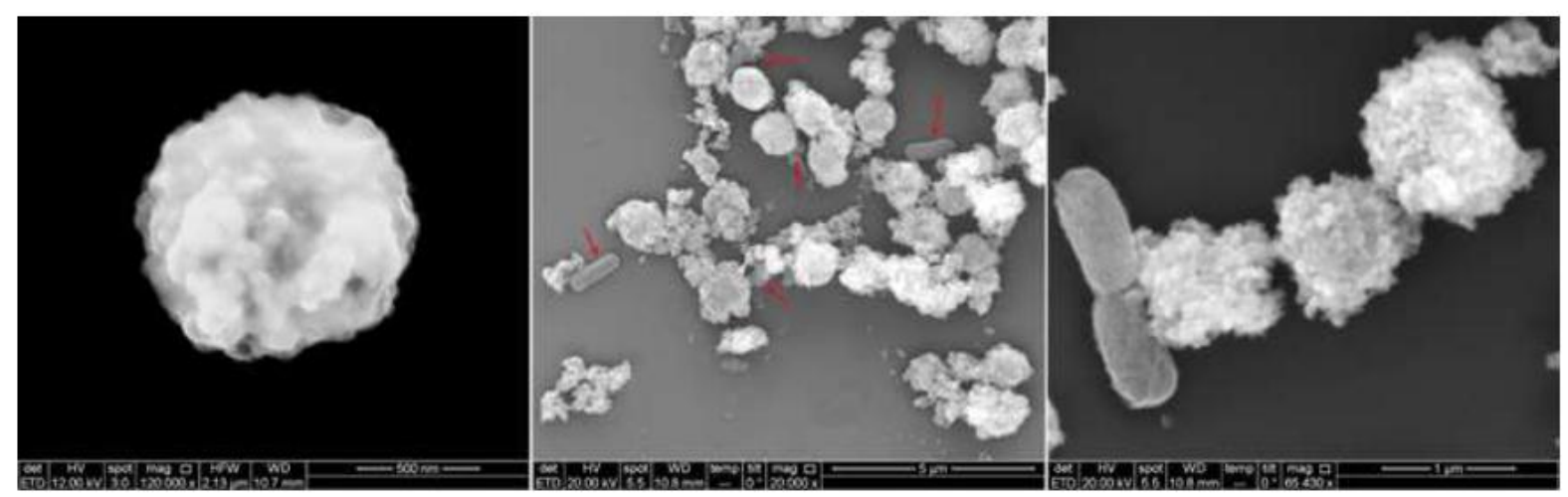

Fig.1.
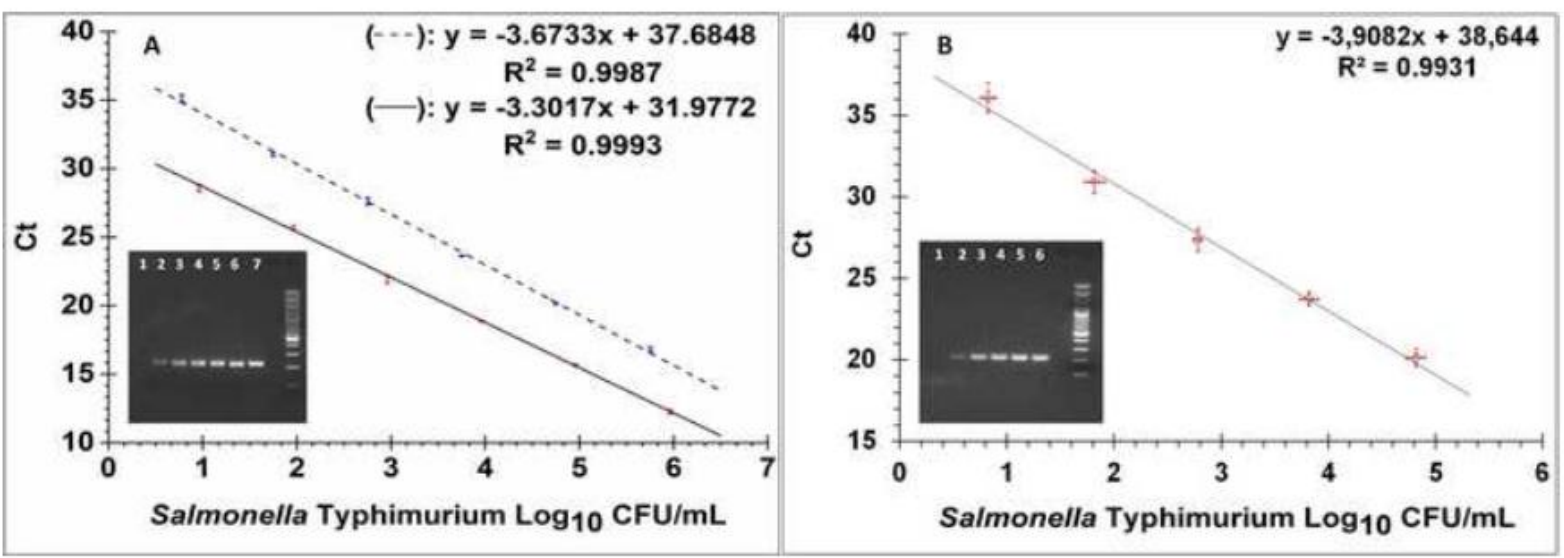

Fig. 2. 

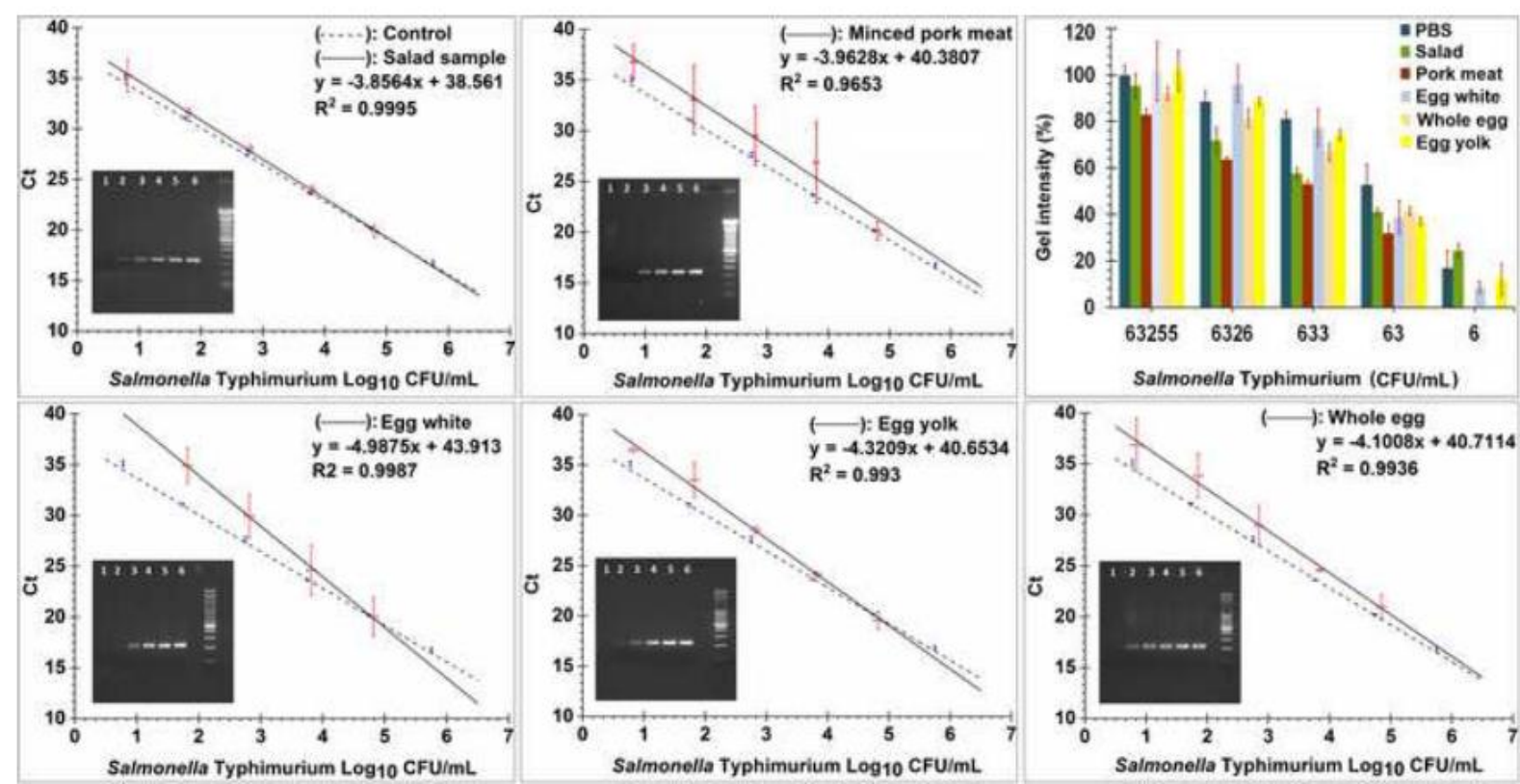

Fig. 3. 
Table 1. Comparison of capturing efficiency of anti-salmonella antibody immobilized magnetic bead (based on the XLD plate counts, $n=4$ ) and relative PCR efficiencies for Salmonella Typhimurium spiked in PBS and different food samples.

Spiked concentration: $1012 \mathrm{CFU} / \mathrm{mL}$

$\begin{array}{llll}\text { Nature of the sample } & \begin{array}{l}\text { Concentration left } \\ \text { in the supernatant }\end{array} & \begin{array}{l}\text { aCapturing } \\ \text { efficiency (\%) }\end{array} & \begin{array}{l}{ }^{\mathrm{b}} \text { Relative PCR } \\ \text { efficiency (\%) }\end{array} \\ & (\mathrm{CFU} / \mathrm{mL}) & & \end{array}$

1. Standard curve of

Not applicable

Not applicable 100

Salmonella Typhimurium

with magnetic bead

2. PBS

50

95.12

92.06

3. Salad sample

85

91.71

93.7

4. Egg white

80

92.19

67.3

5. Egg yolk

110

89.27

80.75

6. Whole egg

50

95.12

86.42

7. Minced pork meat

145

85.85

90.38

${ }^{a}$ Capturing efficiency was calculated based on the difference of Salmonella Typhimurium concentration left in the reaction supernatant after magnetic concentration and initial spiked concentrations.

${ }^{\mathrm{b}} \mathrm{PCR}$ efficiency was calculated using Eq 1 . The relative PCR efficiency for different food samples was calculated comparatively considering PCR efficiency of standard curve generated in the presence of magnetic bead as $100 \%$. 


\section{ACCEPTED MANUSCRIPT}

Table 2. Assessment of precision of the integrated immuno-magnetic direct PCR method in the spiked food samples. A total of 60 samples were tested of which 55 were reported positive and 5 were false negative. Values were normalized to $100 \%$.

\begin{tabular}{lcc}
\hline & PBS & Food samples \\
\hline Average recovery (\%) & 86 & \\
Test positive (\%) & 93.3 & 91.66 \\
Test negative (\%) & 6.66 & 8.33 \\
False positive (\%) & 0 \\
False negative (\%) & \multicolumn{2}{c}{8.33} \\
Relative accuracy (\%) & \multicolumn{2}{c}{98.32} \\
Relative specificity (\%) & \multicolumn{2}{c}{100} \\
Relative sensitivity (\%) & \multicolumn{2}{c}{91.66} \\
Cohen's kappa index & \multicolumn{2}{c}{0.88} \\
\hline
\end{tabular}




\section{Highlights}

- An integrated immuno-magnetic direct PCR method to detect Salmonella Typhimurium directly from food samples.

- Ultra-sensitive detection without enrichment and DNA extraction steps.

- High precision with a relative accuracy of $98.3 \%$ and a sensitivity of $91.6 \%$ in the food samples.

- Rapid detection (within $3 \mathrm{hrs}$ ) with lowest detection limits (2-3 CFU/mL). 